\title{
Use of Bone Transport in the Management of Large Diaphyseal Tibial Defects
}

\author{
Cary Fletcher* \\ Department of Orthopedics, Saint Ann's Bay Regional Hospital, Jamaica
}

Submission: November 22, 2017; Published: December 18, 2017

*Corresponding author: Cary Fletcher, Orthopaedic Surgeon, Saint Ann’s Bay Regional Hospital, 1 Seville Road, Saint Ann’s Bay, Saint Ann, Jamaica, Tel: 1-876-9222273; Email: c.fletch30@yahoo.com

\begin{abstract}
Large bony defects usually occur following high energy open injuries or post debridement. The tibial shaft is the commonest site of these defects. Historically, the treatment was primary amputation. Limb salvage techniques are the current standard of care and options include: staged procedures inclusive of dead space management, soft tissue coverage and subsequent bone grafting, vascularised bone grafting and distractraction osteogenesis. The simultaneous treatment of bone loss, infection, non-union, deformity and leg length discrepancy makes bone transport an extremely valuable treatment option. Due to prolonged treatment times and various potential complications, proper patient selection is mandatory. While it is not a panacea, it remains the most versatile treatment option for complex soft tissue with large bony defects.

Keywords: Bone transport; Tibial; Diaphyseal; Defects
\end{abstract}

Abbreviations: SF-36: 36 Item Short Form survey; FWB: Full Weight Bearing

\section{Introduction}

Surgical reconstruction of tibial bone defects is a challenging problem [1-4]. The bone defect is often secondary to high energy trauma or post debridement [1,5-7]. Injury of muscles, tendons and joints often accompany these defects [1]. Historically, injuries involving large skeletal defects were treated by primary amputation. Modern techniques of fracture stabilisation and reconstruction allow for limb salvage [2].

\section{Discussion}

The challenge of managing a segmented skeletal defect is a potentially humbling experience. Knowledge and skill are required to overcome this challenge, as well as ingenuity and patience $[2,6-8]$. Segmental injuries to the tibia are rare and difficult to treat [9]. Skeletal defects usually follow severe open trauma where bone may be lost at the time of injury or debridement $[5,7,10]$. The tibia is the most common site of bone loss after a fracture because of its subcutaneous position $[2,7,9]$. Within the tibia, the diaphysis is the most common site of injury $[2,9]$. When Watson et al. [10] reviewed several series involving Grade 3 open tibial injuries, the results were predictably worse with patients who had significant bone loss. Christian et al. [11] stated that Grade 3B tibial fractures associated with diaphysial bone loss and marked soft tissue loss is the standard by which institutions measure their success in treating complex open fractures.
Historically, amputation was the treatment for most segmental bone defects [12]. There are currently different options for reconstruction if limb salvage is chosen. These include:

i. Staged procedures which include dead space management, management of overlying soft tissue defects, followed by bone grafting,

ii. Vascularised bone or osteocutaneous transfer and

iii. Distraction osteogenesis [13]

Autologous cancellous bone grafting was once the hallmark of skeletal defect management [14]. The donor sites, however, are limited and constitute an absolute limit on the quantity of fresh autologous cancellous bone available to fill the defect $[8,14]$. The large volume of bone needed to fill a defect greater than $6 \mathrm{~cm}$ requires multiple donor sites, thereby increasing morbidity $[8,14]$. Non-vascular autogenous or allogenic bone grafts relies on surrounding soft tissue to withstand operative manipulation and to re-vascularise the graft, making it unsuitable in many instances [15]. It is especially unsuitable in the management of large defects [7].

An ipsilateral nonvascularised fibula is not very strong and there is poor muscle function [7]. Other potential complications are peroneal nerve paresis and infection [16]. It does allow 
for acute spanning of the defect, has limited donor morbidity and special equipment and microvascular techniques are not required $[7,16]$. This procedure is also said to preserve a major lower limb artery, and achieve a bone defect reconstruction while retaining periosteal and endosteal circulation [16]. Han et al. [17] had favourable results when using vascularised fibular grafting to fill a post traumatic defect, in an environment with good local blood supply and rigid fixation. Weiland et al. [18] noted that early fracture of the transplanted bone is a common complication. This is partly due to the fact that the transported fibula takes years to hypertrophy $[4,19,20]$, and it often fails to unite at one or both ends [19]. The complication rates are fairly high. Other complications reported include transient palsy of the superficial peroneal nerve, contracture of the flexor hallucis longus and valgus deformity of the ankle [21]. Graft fracture is the commonest late complication [21]. Avoidance of weight bearing six months post fracture and the need for a protective orthosis two years postoperatively have also been recommended [21]. Vascularised fibular grafting is mainly indicated for large defects where immediate restoration of skeletal continuity is desirable [7].

Bone transport has successfully been used for acute and late reconstructive bone loss [22], however not much attention has been paid to the acute management of a segmental tibial defect utilising the Ilizarov fixation [9]. Rose [23] acutely utilised the Ilizarov technique in two patients with bone defects $(9 \mathrm{~cm}$ and $8 \mathrm{~cm}$, respectively). Postoperatively, they both had a significant limp and joint stiffness, but had no pain and could perform activities of daily living. Sen et al. [3] studied ten patients who had concomitant soft tissue and bony defects. The external fixation time was 8.0 months (four to thirteen), mean bone healing was 8.8 months (five to fourteen) and mean follow time was 43.5 months. All fractures healed; there were no re-fractures post frame removal and four required bone grafting at docking site. The majority were deemed to have excellent results based on the state of union, absence of infection, deformity, limb length discrepancy and problems at the docking and regenerate sites. El-alfy et al. [6] were also able to successfully use bone transport to manage composite soft tissue and bone defects in ten out of eleven patients. The soft tissue defects ranged from 3 by $4 \mathrm{~cm}$ to 5 by $14 \mathrm{~cm}$ and bone defects ranged from 4 to $14 \mathrm{~cm}$.

Mekhail et al. [4] utilised bone transport in eighteen type three open fracture cases with a mean follow up of 68.7 months. Using the SF-36 scoring system, he found that two patients perceived that they had excellent results, ten good and four fair. Eighteen patients were satisfied. There were 20 minor complications and 19 major complications, including two transtibial amputations and four fractures at the docking site. Frame related complications are the commonest complications of bone transport, followed by non-union of the docking site [22]. In an attempt to avoid delayed union or non-union, some advocate for routine bone grafting of the docking site after removing granulation tissue at that site $[1,3,4,8]$. The rationale for routine bone grafting is to obtain early union, shorten external fixation time and to avoid re-fracture [24]. Biologic factors are necessary for normal healing at the fracture site [22].

Autogenous iliac crest grafting, allographic and recombinant materials have been used to augment and improve consolidation of the docking site [22]. When necessary, only a small volume is required [8]. In an attempt to limit complications which are potentially numerous, meticulous evaluation of radiographs and supervision are necessary [4]. The lengthy treatment times sometimes imposes psychosocial hardships, including stress and pain on the patient and their relatives [1,4]. Using bone transport, missing osseous tissue of any length may be constructed without using bone graft $[14,19]$. Bone transport is particularly valuable in developing countries where there is an absence of bone banks [14]. With large defects, 2 bony fragments may be transported toward each other to speed up closure of the defect [19].

The Ilizarov technique is effective in treating complicated open fractures with bone loss, allowing for simultaneous treatment of bone loss, infection, non-union, deformity and leg length discrepancy $[4,16,25,26]$. It is invaluable in the management of sequelae of open tibial fractures and treatment should be individualised to the patient $[27,28]$. It is most commonly used in the tibia [29].

The components of distraction histiogenesis include

a. The use of stable external fixation which applies forces that produce lengthening, angular correction or bone transport,

b. Corticotomy or Osteotomy of bone and

c. A post Operative period [29].

Corticotomy is usually performed proximally and the bone segment is transported distally until it reaches the docking site of the distal fragment [30]. The corticotomy is performed through healthy bone some distance away from the defect $[22,31]$. The segment of bone between the corticotomy and the defect are fixed with half pins which are attached to components of the apparatus. Via gradual distraction, the corticotomy region is elongated while the defect is being compressed [31]. Of note, only Ilizarov himself has been able to achieve a corticotomy. An osteotomy is carefully performed subperiosteally and efforts are made to avoid direct damage to the medullary canal [25]. Surrounding soft tissue provides the primary periosteal blood supply. When this is compromised, poor quality regenerate may occur [22]. In a delayed segmental tibial defect, distraction osteogenesis may also be done through a high energy fracture [32].

The post operative period may be divided into latency, distraction and consolidation [29]. Latency refers to the period from frame application and corticotomy to lengthening 
initiation, where the cut bone surfaces are eventually bridged by callus [29]. Aronson [33] noted in the literature that the latency period enhances bone formation. The new bone formation or regenerate is then involved in the distraction phase. The distraction force is exerted on a bone segment while filling a defect. The fixation construct allows controlled movement of the bone projectile. Strains across the osteogenic zone trailing the projectile must be controlled, in magnitude and in the temporal application rate during the distraction phase. The projectile is moved with a precise orientation; therefore the cortical surfaces at the target site will be aligned aronson [28]. Ilizarov [34] made several ultra-structural and biochemical observations. He noted a growth zone in the centre of the regenerated region where active osteogenesis occurred throughout the influence of tension stress. Collagen fibres are oriented parallel to the tension vector, upon which osteoblasts have laid down osteoid tissue [34]. The osteoid tissue gradually incorporates into newly formed bone trabeculae in the regions furthest away from the central growth layer, both proximally and distally [34]. With the increase in osteoblastic activity at the corticotomy site, bone transport is considered an anabolic treatment [35]. Under the influence of tension stress, active osteogenesis in the distraction zone omits the cartilaginous phase if the external fixation construct is rigid [34]. It therefore occurs mainly via intramembranous ossification [36].

Stable external fixation is also required to allow compression of the docking site [30]. This prevents disruption of the blood supply, which is important in the facilitation of the migration of pluripotential cells [22]. Angiogenesis occurs along the tension vector as well [34]. After the elongation period, the growth zone is gradually ossified [34]. The consolidation phase involves maturation and corticalisation of the regenerate before frame removal [29]. When transportation is extremely long, the docking site heals prior to consolidation of the regeneration. If the regenerate is inadequate, late deformation and collapse results [22]. Treatment of these complications are problematic and avoidance is ideal [22]. The regenerate may be percutaneously augmented using various orthobiologic adjuvants in order to reduce the consolidation interval before frame removal [22]. It is easier to treat an inadequate docking than inadequate regenerate (e.g. deformation, collapse, recurrent deformity) [22].

Bone transport is considered an ideal treatment for large skeletal defects of any size without limb shortening [7,37]. It allows for decreased need for casting post operatively, or bracing due to rapid corticalisation of regenerate bone and decreases need for bone grafting [12,14,33]. To reduce the treatment time in some cases, double level transportation allows healing to occur more rapidly than single level [4]. The lengthened muscles often get mechanically disadvantaged, leading to decreased range of motion of distal joints [24]. Thus knee and ankle stiffness may occur during bone transport $[20,28]$. The stiffness is due to the origins and insertions of muscles which are attached to the intercalary segment becoming stretched [8]. Concomitant deformity and soft tissue problems may be addressed simultaneously $[7,33]$.

Associated techniques include gradual or acute shortening. After a healed, shortened limb, re-establishing limb length may be achieved using rapid lengthening over an intramedullary nail using autodistractor devices that eliminate patient directed adjustments [22]. Intrameduullary nails have been made with lengthening capacity but it is rarely possible to perform a closed intramedullary osteotomy in the tibia [2]. Gradual shortening of bone defects followed by re-lengthening is a successful method of treating a tibial gap non-union [3]. Shortening may relax the tension of the soft tissues, improve vascularity, reduce neurogenic pain and allow primary closure or coverage $[7,23,24]$. Shortening may result in excessive soft tissue swelling and redundancy [7]. Bone transport may also be combined with ipsilateral vascularised fibular grafting [23].

Circular frames are more popular than unilateral frames because of increased stability and increased flexibility of frame configuration which gives the increased scope for correcting multiple pathologies simultaneously [2]. The design of the circular frame allows axial compressive forces at the fracture site to provide a dynamic osteosynthesis system. This allows for early mobilisation unlike techniques involving bone grafting [25]. The Ilizarov fixator holds bone fragments in proper alignment while allowing weight bearing during bone transport [14]. The weight bearing contact between fracture ends stimulates regeneration [25]. Despite prolonged treatment times, FWB avoids disuse osteoporoses [4].

Advances in the pin design have reduced the complexity of external devices as well as pin and frame related complications [22]. Unilateral frames are however, generally better tolerated by patients [12].

Ilizarov used an all wire construct which had the following disadvantages:

i. Pain and contracture of adjacent joints due to muscle and tendon transfixation,

ii. Increased risk of neurovascular impalement,

iii. Olive wires are more difficult to remove, and

iv. 90-90 placement not always possible, which compromises stability [38].

The Ilizarov assembly may be divided into:

a. Conventional wires,

b. Hybrid traditional minimal half pins, and

c. Hybrid advance maximal half pins.

Half pins removes some of the disadvantages of the all wire construct. It is user friendly, less time consuming, has 


\section{Orthopedics and Rheumatology Open Access Journal}

better patient tolerability and aids in earlier physiotherapy [38]. Insertion of two half pins perpendicular to each other is more stable than the construct with conventional wires. It resists muscle contractures resulting in a decreased incidence of muscular imbalance between compartments. This reduces the incidence of malalignment of the docking site [24]. The complexity of the frame directly impacts on the complications associated with the frame. Multiple transfixion wires may cause tethering of large musculotendinous structures, pin tract infection and chronic pain [22]. Grade 2 tissue inflammations with wire loosening may be treated with local wound care, intravenous antibiotics and wire retensioning [3]. Infected half pins have to be removed in more severe local infections [3]. Recent frame configurations incorporate multiple half pin arrangements which allow constant adjustment of the docking site with less potential for malalignment [22]. Hydroxyapatitecoated pins have reduced the incidence of pin tract infections and chronic pain by reducing the fibrous tissue at the pin bone interface, while allowing for improved direct bone apposition [22].

It must be noted that the patients are often the breadwinner of their family and this prolonged treatment with frequent hospitalisations may present a financial burden [28] with significant time away from the job and possible multiple surgeries, depression is not uncommon [28]. Despite this, it has been found that pain relief and eventual functional outcome are more important to patients than speed of treatment once a detailed explanation of the procedure and its complications is provided to the patient [39]. Functional outcome in addition to bony outcome is used to assess efficacy of treatment [1]. Providing support for the patient is also important for patient satisfaction [39]. This allows patients to have reasonable functional expectations [4]. Bobroff et al. [37] in a 10 year follow-up of 12 patients who averaged $9.45 \mathrm{~cm}$ ( 4 to $20 \mathrm{~cm}$ ) of tibial defects achieved good or excellent results in nine patients. The two patients who did not achieve union were both smokers. Patient selection is critical and both surgeon and patient must understand the lengthy treatment time and considerable number of complications [26].

There has been little documented data on the functional outcome following bone transport of a distal tibial defect [40]. When a tibial corticotomy is proximal, the bony segment which is distally transported to reconstruct the defect will cause muscles or parts of muscles attached to the transported segment to shorten. This is the first reference to investigate the response of muscle to shortening. Gait analysis revealed significant kinetic and kinematic differences between affected and unaffected limbs. The affected limb had decreased stance time which was especially marked in patients with equinus deformity. Dynamometric tests revealed decreased moment and generating potential as well as decreased electromyographic studies which explain patient's reluctance to participate in physically demanding activities [40].
Poor function may be due to soft tissue oedema and joint stiffness including knee, ankle and subtalar joints. Knee stiffness may be overcome by physiotherapy however foot and ankle stiffness may persist and worsen despite bony union and may cause a poor result [28]. Rose [14] noted that all three of his patients developed knee flexion contractures during treatment despite physiotherapy; however this resolved post removal of frame. All patients in the Madhusudhan et al. [30] study ended with more sedentary, less demanding jobs and it was noted that patient motivation, social and economic support are all crucial to the final outcome.

\section{Conclusion}

Bone transport remains the most versatile, effective treatment for complex cases involving extensive bony and soft tissue injuries. While it is not a panacea, it is an important treatment method in circumstances with no acceptable alternatives; however drawbacks include lost time and loss of resources, intensive treatment and multiple complications associated with its use. For optimal functional results, transfer to a specialist unit, patient selection, emotional, functional and social support is compulsory.

\section{Conflict of Interest}

Nil economic or conflict of interests.

\section{References}

1. Paley D, Maar DC (2000) Ilizarov bone transport treatment for tibial defects. J Orthop Trauma 14(2): 76-85.

2. Keating JF, Simpson AHRW, Robinson CM (2005) The management of fractures with bone loss. J Bone Joint Surg Br 87(2): 142-150.

3. Sen C, Eralp L, Gunes T, Erdem M, Ozden VE, et al. (2006) An alternative method for the treatment of nonunion of the tibia with bone loss. J Bone Joint Surg Br 88(6): 783-789.

4. Mekhail AO, Abraham E, Gruber B, Gonzalez M (2004) Bone transport in the management of posttraumatic bone defects in the lower extremity. J Trauma 56(2): 368-378.

5. Raschke MJ, Steenlage ES, Stange R, Schmidmaier G (2002) External fixation, intramedullary nailing, and bone transport: indications and limitations. Tech in Orthopaedics 17(2): 197-206.

6. El-Alfy B, El-Mowafi H, El-Moghazy N (2010) Distraction osteogenesis in management of composite bone and soft tissue defects. Int Orthop 34(1): 115-118.

7. DeCoster TA, Gehlert RJ, Mikola EA, Pirela-Cruz MA (2004) Management of posttraumatic segmental bone defects. J Am Acad Orthop Surg 12(1): 28-38.

8. Green SA (1994) Skeletal defects. A comparison of bone grafting and bone transport for segmental skeletal defects. Clin Orthop Relat Res (301): 111-117.

9. Oztürkmen Y, Karamehmetoğlu M, Karadeniz H, Azboy I, Caniklioğlu M (2009) Acute treatment of segmental tibial fractures with the Ilizarov method. Injury 40(3): 321-326.

10. Watson JT, Anders M, Moed BR (1995) Management strategies for bone loss in tibial shaft fractures. Clin Orthop Relat Res (315): 138-152.

11. Christian EP, Bosse MJ, Robb G (1989) Reconstruction of large diaphyseal defects, without free fibular transfer, in Grade-IIIB tibial fractures. J Bone Joint Surg Am 71(7): 994-1004. 
12. Kesemenli C, Subasi M, Kirkgoz T, Kapukaya A, Arslan H (2001) Treatment of traumatic bone defects by bone transport. Acta Orthop Belg 67(4): 380-386.

13. Webb L (2001) Bone defect nonunion of the lower extremity. Tech in Orthopaedics 16(4): 387-397.

14. Rose RE (2002) The Ilizarov technique in the treatment of tibial bone defects. Case reports and review of the literature. West Indian Med J 51(4): 263-267.

15. El-Sayed M, El-Hadidi M, El-Adl W (2007) Free non-vascularised fibular graft for treatment of post-traumatic bone defects. Acta OrthoP Belg 73(1): 70-76.

16. Theos C, Koulouvaris P, Kottakis S, Demertzis N (2008) Reconstruction of tibia defects by ipsilateral vascularized fibula transposition. Arch Orthop Trauma Surg 128(2): 179-184.

17. Han CS, Wood MB, Bishop AT, Cooney WP (1992) Vascularised bone transfer. J Bone Joint Surg Am 74(10): 1441-1449.

18. Weiland AJ, Moore JR, Daniel RK (1983) Vascularized bone autografts. Experience with 41 cases. Clin Orthop Relat Res 174: 87-95.

19. Green SA, Jackson JM, Wall DM, Marinow H, Ishkanian J (1992) Management of segmental defects by the Ilizarov intercalary bone transport method. Clin Orthop Relat Res 280: 136-142.

20. Reigstad A (1997) Soft tissue defects and bone loss in tibial fracturestreatment with free flaps and bone transport. Acta Orthop Scand 68(6): 615-622.

21. Minami A, Kasashima T, Iwasaki N (2000) Vascularised fibular grafts. An experience of 102 patients. J Bone Joint Surg Br 82(7): 1022-1025.

22. Watson JT (2006) Distraction osteogenesis. J Am Acad Orthop Surg 14(10 Spec No.): S168-S174.

23. Rose REC (2010) Acute Trauma Applications of the Ilizarov Method. The Internet Journal of Orthopedic Surgery 16(1).

24. Song HR, Cho SH, Koo KH, Jeong ST, Park YJ, et al (1998) Tibial bone defects treated by internal bone transport using the Ilizarov method. Int Orthop 22(5): 293-297.

25. Dagher F, Roukoz S Compound tibial fractures with bone loss treated by the Ilizarov technique. J Bone Joint Surg Br 73(2): 316-321.

26. Bumbasirević M, Tomić S, Lesić A, Milosević I, Atkinson HD (2010) War-related infected tibial nonunion with bone and soft-tissue loss treated with bone transport using the Ilizarov method. Arch Orthop Trauma Surg 130(6): 739-749.

27. El-Rosasy MA (2008) Appraisal of the role of external skeletal fixation in the management of sequelae of open tibial fractures. Indian J Orthop 42(4): 420-425

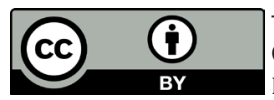

This work is licensed under Creative

Commons Attribution 4.0 License

DOI: 10.19080/OROAJ.2017.09.555764
28. Madhusudhan TR, Ramesh B, Manjunath K, Shah HM, Sundaresh DC, et al. (2008) Outcomes of Ilizarov ring fixation in recalcitrant infected tibial non-unions - a prospective study. J Trauma Manag Outcomes 2(1): 6 .

29. Murray JH, Fitch RD (1996) Distraction Histiogenesis: Principles and Indications. J Am Acad Orthop Surg 4(6): 317-327.

30. Aronson J, Johnson E, Harp JH (1989) Local bone transportation for treatment of intercalary defects by the Ilizarov technique. Biomechanical and clinical considerations. Clin Orthop Relat Res 243: 71-79.

31. Ilizarov GA (1989) The tension-stress effect on the genesis and growth of tissues: Part II. The influence of the rate and frequency of distraction. Clin Orthop Relat Res 239: 263-285.

32. Saghieh S, Ghanem E, Sagherian B, Karam M, Afeiche N (2008) Distraction osteogenesis in a segmental tibial delayed union. Eur J Orthop Surg Traumatology 18(3): 237-242.

33. Aronson J (1997) Current Concepts Review - Limb-Lengthening, Skeletal Reconstruction and Bone Transport with the Ilizarov Method J Bone Joint Surg Am 79(8): 1243-1258.

34. Ilizarov GA (1989) The tension-stress effect on the genesis and growth of tissues. Part I. The influence of stability of fixation and soft-tissue preservation. Clin Orthop Relat Res 238: 249-281.

35. Little DG, Ramachandran M, Schindeler A (2007) The anabolic and catabolic responses in bone repair. J Bone Joint Surg Br 89(4): 425-433.

36. Morgan EF, Gleason RE, Hayward LN, Leong PL, Palomares KT (2008) Mechanotransduction and fracture repair. J Bone Joint Surg Am 90(1): 25-30.

37. Bobroff GD, Gold S, Zinar (2003) Ten year experience with use of Ilizarov bone transport for tibial defects. Bull Hosp Jt Dis 61(3-4): 101107.

38. Baruah RK (2007) Ilizarov methodology for infected non union of the Tibia: Classic circular transfixion wire assembly vs. hybrid assembly. Indian J Orthop 41(3): 198-203

39. Marsh DR, Shah S, Elliott J, Kurdy N (1997) The Ilizarov method in nonunion, malunion and infection of fractures. J Bone Joint Surg Br 79(2): 273-279.

40. Giannikas KA, Maganaris CN, Karski MT, Twigg P, Wilkes RA, et al. (2005) Functional outcome following bone transport reconstruction of distal tibial defects. J Bone Joint Surg Am 87(1): 145-152.

\section{Your next submission with Juniper Publishers} will reach you the below assets

- Quality Editorial service

- Swift Peer Review

- Reprints availability

- E-prints Service

- Manuscript Podcast for convenient understanding

- Global attainment for your research

- Manuscript accessibility in different formats

( Pdf, E-pub, Full Text, Audio)

- Unceasing customer service

Track the below URL for one-step submission https://juniperpublishers.com/online-submission.php 